\title{
SELF-GOVERNING PRODUCTION GROUPS: TOWARDS REQUIREMENTS FOR IT SUPPORT
}

\author{
Peter H. Carstensen and Kjeld Schmidt \\ The IT University of Copenhagen, Denmark, (carstensen, schmidt)@it-c.dk
}

\begin{abstract}
Many manufacturing enterprises are introducing various forms of flexible work organizations on the shop floor. However, existing computer-based production planning and control systems pose serious obstacles for self-governing groups and other kinds of shop floor control to become reality. In order to understand and overcome these obstacles we have undertaken a series of six field studies in manufacturing companies. Based on our findings from these studies - and inspired by the research field of Computer Supported Cooperative Work - we present a first set of requirements and principles for IT-based systems for selfgoverning production groups. The intention is to support responsible workers in their situated planning, control and coordination of shop floor activities.
\end{abstract}

\section{INTRODUCTION}

For most of the 20th century, manufacturing has epitomized a work organization characterized by radically centralized and very detailed and rigid regulation of work in which the individual's sphere of activity is reduced to a small repertoire of monotonous movements (Blauner, 1964; Braverman, 1974). The result was a high rate of labor turnover. To deal with this problem, sociologists and ergonomists suggested radical changes to the work organization in the form of job enlargement and introduction of production groups on the shop floor that would have control over day-to-day task allocation and production planning and control. Over the following years, a number of 'socio-technical' experiments with work organizations based on higher degrees of local control were carried out, often successfully (Hirschhorn, 1984) but these principles were never implemented on a large scale. However, a series of fundamental changes over the last two decades have placed the issue of the work organization in manufacturing on the agenda again. Faced with turbulent markets, industrial enterprises are opting for strategies that involve shorter product life cycles and increasing product diversification, which in turn requires a reduction of inventories and buffer stocks, extremely short lead times, shrinking batch sizes, concurrent processing of multiple different products and orders, etc. (Gunn, 1987). To meet these requirements, industrial work organizations must be able to adapt rapidly and diligently to changing demands in a concerted and integrated way. 
To cope with these demands, a large number of manufacturing enterprises are now trying to introduce various forms of flexible work organizations on the shop floor (Womack et al., 1990; Durand et al., 1999). While the precise organizational forms vary, they are basically characterized by local control over job allocation and day-to-day production planning and control, often called 'autonomous' or 'selfgoverning' production groups. When serious attempts at shop floor control are being made, it very soon becomes quite evident, however, that existing computer-based production planning and control systems pose severe obstacles for self-governing production groups and other kinds of shop floor control to become reality (Odgaard, 1994). They were designed for an entirely different world.

In view of these experiences we have initiated investigations with the objective of developing novel forms of production planning and control systems that would specifically address the requirements of self-governing production groups and other kinds of shop floor control. Our work has been heavily inspired by the field of Computer Supported Cooperative Work (CSCW). Here cooperative work is seen as inexorably distributed in the sense that actors are acting, and have to act, on partial knowledge of the state of affairs (Schmidt, 1991). There is thus, in principle, no allknowing agent. Orderly coordination is accomplished through the local actions and interactions of actors who have only local control. The presumptions of MRP systems, that the planning department of the enterprise is able to predict and control, in essence, the manifold interdependent activities of a manufacturing enterprise, is illusory, and in flexible manufacturing the enormous systemic costs of maintaining this illusion have become evident. However, cooperating groups do cope with the enormous complexity arising from the fact that their activities interdependent and yet distributed - through organizational constructs such as plans, schedules, procedures, etc. Such constructs do not in every detail or determine local action; they are rather 'resources for situated action' (Suchman, 1987); they are normative constructs that, to competent members, specify the appropriate next step to be taken, unless the actors have reasons not to do so (Schmidt, 1999).

Even when faced with turbulent environments, the models of interdependencies underlying coordinative constructs are far from useless, but they are used in a quite different manner than simple plan execution. They may indicate the desirable end result of the effort, they may be provide reasonably useful insight into the likely effects of an action, or they may be modified temporarily and then used for coordinative purposes even if the system otherwise would be beyond its bounds (Carstensen and Sørensen, 1996; Grinter, 1997).

To investigate and inform this approach and these ideas further field studies were conducted at six different manufacturing companies in Denmark. The primary purpose was to provide a proper basis for a detailed discussion of requirements for IT support for self-governing production groups. This paper presents the central findings and conclusions from the field studies and briefly discuss overall requirements and principles for applicable IT support.

\section{APPROACH}

In order to obtain a coherent understanding of complex work settings and the work conducted there, field studies are essential (Yin, 1989; Orlikowski, 1993). This 
paper is based on data collected in six such studies of more or less self-governing groups of shop floor workers. The studies focused on planning and coordination activities of the members of the groups and the resources and techniques used by them in these activities.

Each of the six studies was performed over a period of a few months and was mainly based on qualitative interviews (Patton, 1980), observation studies, and analyses of various coordinative artifacts and other documents (e.g., weekly work plans, schedule boards, production plans, and log books). Each of the studies involved 5-10 in-depth interviews as well as observational and other studies.

The first study was conducted in 1998-99 and resulted in a set of preliminary requirements for IT support which were in turn expressed in the design of a 'horizontal prototype' (cf. Carstensen et al., 1999). As a follow-up to this study, five additional studies were undertaken during 2001. In May 2001 the initial findings and conclusions from the entire range of studies were summarized in a report that was discussed at a two-day seminar with group members, managers, and shop stewards from participating companies.

The studies were not ethnographies but were focused on a set of defined issues and were structured accordingly. In particular, the five second-stage studies focused on a number of topics that were identified from the first study. The research approach taken can be characterized as qualitative research heavily inspired by theories and conceptualizations from the field of CSCW and from other studies of complex work settings.

\section{THE SETTINGS}

In the process of selecting the six companies and groups, we aimed at covering a range of quite different types of production, different kinds of organization of work, different regimes of self-governance, etc.. These differences notwithstanding, there were some striking similarities in the problems the groups were facing in their daily struggle with planning their activities, monitoring progress, rescheduling, etc.

The six studies were conducted at:

- ABB Energy and Industry, a factory producing facilities for the distribution of electrical power from power plants to consumers. We studied a group of 15-20 workers processing metal plates. The core activities were punching, cutting, canting, welding, and surface treatment. This group had an internal planner (the role rotated among members). The planner was responsible for daily planning and interaction with the central planning department.

- Odense Steel Shipyard, one of the largest shipyards in Europe. We studied a group of 18 workers producing large steel profiles. The group was headed by an appointed foreman who conducted most of the planning, ordering of materials, etc.

- NKT Cables, a leading European cable manufacturer. We studied three groups with 12-24 members. The groups had been self-governing for a decade and handled most of the staffing and production planning.

- Blika. a medium-size manufacturing company producing steel wardrobes and steel wire products. We studied two groups (each having 11 members). The groups have been self-governing for more than eight years. 
- Man B\&W Alpha Diesel, a leading manufacturer of propulsion plants for smaller and medium-sized ship types. We studied two groups, a group in parts production and a group in assembly. The groups at Man B\&W have appointed coordinators within the groups. The coordinators handle most of the production planning, materials procurement, etc. In peak situations the groups might appoint extra coordinators if necessary.

- Brüel \& Kjær. a leading manufacturer of sound and vibration measurement equipment. We studied a group assembling small amplifiers for sound measuring equipment. This group had 17-20 members and they handled most of the production and staffing themselves. Group members were furthermore responsible for ordering materials and for quality assurance.

The workers in the cases represented different categories of skill and training, from engineers with specialized formal training to operators with no formal training. At ABB the distribution was fifty-fifty, at Lind $\emptyset$ and Man B\&W members generally were trained engineers, whereas workers Blika, NKT and Brüel \& Kjær mostly did not have formal training. There was no correlation between the educational level in the groups and the degree of autonomy enjoyed by the groups. In fact, the members of the most autonomous group of the groups we studied (at Brüel \& Kjær) had not formal training (with one exception).

\section{OBSERVATIONS}

As mentioned there were both similarities and differences among the groups. All of the groups were handling part of the planning activities themselves, although the degree of autonomy differed significantly. In the group at the shipyard a foreman had overall responsibilities, whereas the assembly group at Brüel \& Kjær handled all activities relating to staffing, production planning and control, materials procurement, and quality assurance without even having formal roles.

Some of the groups used existing (centralized) IT systems for their production planning and coordinative activities. A key observation here was that the use of production planning systems caused significant problems, as these systems did not fulfil the users needs for local control, adequate levels of granularity of information, etc.

Although the degrees of autonomy differed among the groups, all groups had control of, and responsibility for, how the work was to be carried out, and thereby control of the division of activities among group members. In some situations this required accounting for who would be available when, who had the required skills for a specific task, etc.

In analyzing our observations we distinguished three general categories of tasks relating to self-governance: Staffing and work allocation, Production planning and control, and Information and experience exchange. In the following each of these will be presented in a little further details.

\subsection{Staffing and Work Allocation}

The activities under this category primarily served to establish a staffing plan indicating who would be working which shifts and, within that framework, who 
would be doing what when. The plans would account for general constraints such as vacations and other planned absences, and would take into account the competencies of the individual workers with respect to the work to be done (e.g., 'is he certified for driving the truck?' or 'is she trained for running the canting center?'). The plans would be updated continually to deal with contingencies such as workers calling in sick or absent for training purposes etc. In one of our studies coordinators would also engage in negotiations related to lending out personnel in situations with excess capacity (in order to ensure 'a proper salary for rest of the members') or, conversely, borrowing actors from other groups in production peak situations.

In most of the groups, staffing plans were established once a week, but they would be updated and re-organized on a daily basis due to changes. To cope with this an overview of the skills and competencies of group members was essential. In most of the groups, however, coordinators were not supported in this regard. The group at Brüel \& $\mathrm{Kjær}$, on the other hand, every year constructed a matrix representation that matched required tasks (and, implicitly, required skills) with members of the group and thus made it visible who had formal training in which tasks or processes.

Work was allocated in terms of a variety of categories, in terms of work stations or locations, in terms of tasks, in terms of time periods, or a combination of these. At $\mathrm{ABB}$ and NKT, for example, allocation was expressed in terms of time period and work station. At Brüel \& Kjær, by constrast, work was generally allocated in terms of locations, but in this case the specific activities to be undertaken at which location was negotiated from situation to situation.

The work allocation and staffing activities also included establishment of plans for general work allocation and job rotation in the following period. Typically such plans were established once every six months or once a year. These plans in turn required plans for meeting the training requirements of members. In about half of our studies it was the groups who themselves established and negotiated these rotation and training plans.

\subsection{Production Planning and Control}

Production planning and control constitute a core set of tasks and a major challenge for many self-governing production groups. The groups must handle and interrelate many very different and yet mutually interdependent constraints and parameters when establishing the plans, such as, for example, deadlines (relative importance of conflicting deadlines), required and possible flows of materials and sub-products, required raw materials or components, required and possible sequences (routing), flexibility in choice of sub-processes and materials, effects of decisions downstream in the production, etc.

In most of the groups, production planning work was undertaken by the group themselves. Some groups had dedicated roles for planning, typically a role that was rotated among group members every second or third month. At Brüel \& Kjær, planning was a separate task which was addressed every Thursday morning by practically all group members.

The initial production planning is typically done on the basis of production orders (requests) generated by some central planning department. Production orders to the groups can be at a very general level ('we need 500 BMR1798 pre-amplifiers 
produced by the end of week $27^{\prime}$ ), or as very detailed task lists in which each and every production process is specified in terms of sequence, workstation, fixtures, materials, components, amount (number, length), CNC-program, etc. The latter is typically lists produced by the central MRP systems. In most cases, however, the groups had to take local and temporary contingencies into account in adopting centrally generated plans, e.g., which of the optional workstations can deliver the required tolerance? how do we handle this member's absence? is there an alternative to this process?

A new version of the production plan was typically established on a daily basis or on a weekly basis. When the groups finished the planning, the plans were typically negotiated with actors from the central planning department. In some of our cases this negotiation took place before the detailed planning was done (i.e., to inform the planning process), whereas it in other cases was discussed after the detailed planning had illuminated potential problems.

As result of the planning activities, some of the groups had to identify needs for materials and components and order these from the storage or from internal or external sub-suppliers.

Production control, i.e., monitoring progress with respect to plans and rescheduling work in accordance with (previously) unforeseen events and changes, is of course equally important to self-governing groups.

Schematically, core activities of production control work of the groups would include:

Ensuring consistency between the plan and the actual work. This included monitoring progress. There are often major differences between what is foreseen in the plans (e.g. with respect to initial set-up time for a process) and reality. Hence, actors would monitor to what extent the plans were, or could be, fulfilled. Another aspect that the central planning systems did not and could not support was to take space requirements into account. We observed several situations were re-scheduling had to be done due to space requirements. For example, the assembly group next process downstream was two days behind schedule and had therefore no space available for the eight new plates to be produced; these therefore could not be delivered and would block for other processes in the planned flow.

Handling unforeseen events. Events like these occurred both due to defective equipment, lack of (or defective) materials and components, human errors, absence of members with key competencies, changes in demands and priorities from the rest of the factory, etc. In such situations the groups, or the coordinators in the groups, would re-schedule work or reroute work flow. Rescheduling and rerouting often involved negotiations with the central planning departments or production groups down- or upstream in the flow.

Monitoring the flow of materials. This included contacting other groups upstream in the production or suppliers of component or materials so as to ensure availability of components and materials when required. This kind of monitoring activities was of course also often essential internally in the groups, as members were often suppliers to other members. The monitoring activities were more or less undertaken by all actors, i.e., everybody was attentive to the issue of whether they could expect to have the materials required for their individual tasks.

Managing the local storage of materials and sub-components. This had to do with ensuring that the required components and materials were available when 
needed, and keep track of the consumption so that requests and purchase could be handled in time. Two of the groups had an internal storage in which their most common sub-components and materials were stored. The groups were responsible for ordering new materials for the storage when required.

Assuring product quality. Most of the self-governing production groups we observed were responsible for quality assurance of their own products. Some of the groups had a dedicated role responsible for organizing quality assurance work and implementing procedures fulfilling overall company requirements. It was usually a responsibility which the groups were proud of, but at the same time a set of tasks that were sometimes quite unstructured and that were not supported by any standard procedures or systems. We generally found only little systemacity in the collection and distribution of experience among group members.

Requesting assistance. In many situations a group might need support in their work from people outside the group (e.g., order a crane for moving very large components). In these situations the groups themselves would interact with the actors providing the service.

\subsection{Information and Experience Exchange}

In many groups a lot of energy was used on informing each other on changes in plans, material flows, etc. A general observation was that group members are heavily interdependent in their activities and that they, as a consequence of this, spend much time on coordinating and negotiating activities. This was also the case in relation to other groups (e.g., other groups down-stream, central planners, purchasing department, process support technicians, etc.). In many of the situations we have investigated, the members did not have effective and efficient means (or media) for coordinating with each other or with people outside their own group.

Many of the groups were also confronted with requirements regarding accounting for, or documentation of, the processes. Again few support tools were available.

Exchange of experiences and knowledge was a major challenge for all the selfgoverning groups. There was a strong need for collecting and expressing experiences (e.g., 'how long time does it take to produce 200 of the BMR1798?' or 'what is the alternative production process when the canting work station breaks down?'). Although the exchange of such experiences within the groups is important, no facilities currently support this. We have observed a number of 'private' logbooks or photo albums, but such solutions cannot be scaled-up and are fragile over time, as they are not systematic and based on robust and agreed-to classification schemes. The most common means for exchanging experiences was 'war stories' exchanged during breaks, over lunch, etc.

In about half of the studies, production work was widely distributed (in space and time), so that group members could not easily interact with one another on an ad hoc basis. This exacerbated the problems with experience and knowledge exchange. In these cases log-books and note pads were used instead. This information was, however primarily status information, e.g., 'the bending II workstation is unstable avoid complex processes'. 


\section{DISCUSSION: TOWARDS PROPER IT SUPPORT}

As argued above, workers in self-governing groups face serious challenges and problems in handling the administrative, managerial, and coordinative tasks required for planning and managing their work.

\subsection{The Nature of Manufacturing Work}

Along the same line as authors like Harrington $(1979 ; 1984)$ our studies have illustrated some central complexity aspects of manufacturing. In the following we will briefly characterize these and reflect upon the implications for the planning and control of the work.

Manufacturing is essentially and massively material. It's about changing the physical form of things - by changing the geometry of objects and by putting parts together in more or less complex configurations. Manufacturing work is thus not only materially embedded or situated, like all human behavior, and it is not merely materially constrained, like all work. Manufacturing work is fundamentally, inexorably, and continually faced with and dealing with an infinite array of physical, chemical, mechanical, thermodynamic, electrical, biological, etc. objects, processes, constraints, contingencies, inferences, breakdowns, etc.

The work to be planned and managed is therefore extremely variegated, even within the same department, or self-governing group (from one workstation to another, from one situation to another). Due to the different character of the materials, processes, parts, and tools and other equipment, the actors have to manage activities, problems, and challenges that are particular and unique to the setting or situation. Even highly sophisticated attempts at developing models of manufacturing processes (Todd et al., 1994b; Todd et al., 1994a) thus invariably turn out to be strikingly incomplete, in that they cover but a restricted set of processes or planning parameters. Trivial issues of space utilization may for example take precedent over other issues, such as delivery date, economy of scale, lead time, etc. Finished products may for instance take up so much space that the issue of keeping order in the shipping room may require the production plan to be rescheduled. Similarly, in a cable factory the same drum may house multiple pieces of cable and it may be more efficient to reschedule production than to unwind and rewind the drums. Current production planning and control systems (based on MRP technology) cannot express such issues. The actors have no dedicated means for taken these issues into consideration.

The inexhaustible material variety of manufacturing work also means that production planning and control activities cannot be conceived of in abstraction from the very transformation processes that are their target. Production planning and control and process control are both conceptually and practically in an internal relationship'. Production control activities are not external to but rather inexorably conceived of and expressed in term of the material transformation processes. Thus, if production planning and control systems and process control systems are designed in isolation of one another, radical and potentially disruptive impediments to production work are introduced.

Production planning and control systems must thus, at the very least, interface to a vast and open-ended array of other kinds of software systems: process control 
systems for different kinds of processes, CAD/CAM systems, accounting systems, payroll systems, etc.

Finally, most manufacturing processes involve a large variety of qualitatively different processes such as pressing, extruding, cutting, polishing, painting, screwing, assembling, etc., that are typically distributed over a large collection of more or less specialized workstations which, in turn, often will be specialized themselves. Due to the infinite variety of processes, the total process is radically distributed over specialized workstations. Moreover, because manufacturing work is radically distributed, manufacturing work is characterized by very complex interdependencies. Any local contingency may have repercussions up- or downstream, which, to the local decision makers, may be intractable. A system supporting the local planning and control work in the different groups might thus be running in different instances in different, but still interdependent, production groups. The repercussions up- or downstream will affect interaction across these instances of the local planning and control system.

\subsection{Towards IT Support}

Most planning, coordination and control of manufacturing operations are based upon centralized systems build upon models of bills of materials, routings, process specifications, etc. The master production schedule is thus 'the vital control center for the company's manufacturing planning and control system' (Gunn, 1981, p. 9). The enormously complex production control problem is thereby, in theory, reduced to executing this plan.

As argued above, the idea of having a complete model of manufacturing is chimerical, however. One could claim that most existing planning and control work at the shop floor is functioning okay, not because of the central planning systems, but because the human actors are highly flexible and adaptive to the situations occurring. Moreover, as soon as manufacturing companies launch on the course of flexible adaptation, entirely different production control strategies are required, and the kind of support required on the shop floor differs radically from what traditional MRP and similar systems are capable of providing.

Aiming at a centralized system based upon a 'complete model' of the activities is thus not a viable approach to building adequate IT-support systems for shop floor planning and control. Instead, we suggest, we should consider how IT could support the planning, managing, collaboration and coordination activities, and thereby assist intelligent and responsible workers in their situated coordination activities on the shop floor.

However, the radical and inexhaustible variety of manufacturing work takes manufacturing apart from typical application domains for IT. Accounting is essentially manipulation of representations of economic activities. The contingencies of the material world is of minor concern (except when invoices are lost, archives burnt or flooded etc.). More than that, accounting practices are regulated by law and accounting thus offers a large homogeneous market for software houses. The same applies, more or less, to so-called 'office work', that is, the construction and manipulation of documents, which also has been amenable to computerization by means of a limited suite of generic applications (e.g., word processing, spreadsheets and organizers). 
By contrast to such domains, in which IT perhaps can be said to have experienced easy triumphs, manufacturing is not an appropriate domain for (more or less complex) monolithic applications or application systems (such as accounting) or for integrated suites of generic applications (such as 'office work' or desktop publishing). Manufacturing seems to require another, radically different software development strategy than that of the traditional areas of IT deployment. A monolithic application system will invariably create all sorts of problem on the shop floor, as workers strive to make the system fit. The dismal record of the existing monolithic MRP-based production planning and control systems in contemporary manufacturing seems to confirm that. Instead, an open-ended approach seems required.

An open-ended approach must provide a framework (architecture, platform) in which specialized software modules designed to deal with specific tasks of control, coordination, communication, process control etc. can be incorporated and interact in an orderly fashion. To assist intelligent and responsible workers in their situated coordination activities on the shop floor, the underlying models of MRP systems, etc. are not obsolete but must be used - and made useful - in a very different way: constraints that are not essential must be removed or relaxed, so that workers can circumvent or overrule the recommendations of the system when that is deemed appropriate. Furthermore, since it is unlikely that a conceptual model of manufacturing can be defined once and for all, new issues or processes will invariably emerge that need to be included as parameters or resources in the model. It therefore seems as if the framework must provide an abstract notation for defining functionalities, planning and control parameters, interfaces, protocols, etc.

It is beyond the scope of this paper to extend the discussion on architecture further here. We have, however from our studies, identified a set of overall principles for the design of this kind of systems. These can also be seen as an abstract summary of some of our findings:

- Plans are resources for action, not structures that are executed mindlessly. The systems supporting the planning and execution must allow deviations from plans.

- No system should aim at having a 'complete picture'. Our studies have clearly illustrated that situations at the shop floor are contingent. No matter how detailed we aim at registering the events in the production, there will always be 'white spots' in the databases, e.g., Jensen handling the canting machine is ill, Bending Workstation II is causing problems, etc. A large degree of flexibility in the planning in accordance with this kind of knowledge must be provided to the actors.

- The system should provide an open-ended overview of status to the actors. If the actors are to handle and coordinate the activities in a situated manner, they need to have a good overview of the state of affairs. Since it is not possible to foresee the borders (perspective) of the required information, the information must be provided in an open-ended manner, so that the actors themselves are in control of how much overview information they need.

- Actors should have ultimate control. Based on the core assumption that the relevant space of deviations is impossible to foresee - that has been documented many times in our studies - the systems should avoid automation of processes that cannot be overruled by the actors. 
- The system should allow experimentation with plans. It is more or less difficult for actors on the shop floor (or anywhere else) to predict the consequences of changes to plans and schedules. It is therefore important, that planning support systems allow different kinds of experimentation with the plans.

- The perspective and level of detail should be variable and selectable. Our studies indicate that actors sometimes may need to investigate very detailed information, e.g., about a specific production process, whereas they in other situations need an overall picture with a different granularity.

- Education and training in the basic concepts and model are essential. In several of our studies we observed that members had serious problems in understanding and coping with the information provided from the central planning systems. One obvious reason was that key concepts (e.g., bill-ofmaterials) were not fully understood by the actors, and using the information in the systems thus became quite difficult.

- A high degree of usability is self-evident. The fact that the user interface is easy to learn and use is still essential.

Most of these overall principles might appear 'obvious' and we perhaps do not require in-depth field studies to identify them. However, we have not come across shop floor support systems that adhere to these principles, and in most of the settings and situations we have studied it was quite clear that the requirements are far from fulfilled and that the principles are not adhere to at all. And we have no reason at all to expect it to be different in other settings. In fact some of the settings we studied have been carefully and systematically striving to improve the support for the selfgoverning groups for years.

Finally, after having suggested a key role for IT in planning and control of shop floor activities, it is important to emphasize that IT by no means is a panacea. There are a number of areas in which IT cannot support workers, but we believe that IT, combined with other initiatives, can provide a useful tool for self-governing groups

To test out some of the ideas and principles for IT support of self-governing groups, we designed a horizontal prototype of a manning and production planning system. The prototype was based on findings from the first of our six field studies. The prototype is illustrated and discussed in length in Carstensen et al. (1999). The reactions (both from managers and workers) were very positive. To investigate further we conducted the five extra field studies presented in this paper. We believe, that we now have a basis for starting discussions on requirements for IT systems for self-governing groups. We are however aware that much further work is required. For example, work on identifying how different characteristics of the production should be reflected, how the interaction with existing information systems and other technologies should be handled, how a proper IT architecture for this kind of systems should be designed, etc. etc. There is still a long way to go!

\section{ACKNOWLEDGMENTS}

The IDAK project is supported by Industriens Uddannelsesfond. The project was conceived and initiated by Irene Odgaard of the Central Organization of Danish Industrial Workers (CO-Industri) whose support is gratefully acknowledged. Hans 
Jørgen Lynggaard, Alex Skandorff Vestergaard and Uffe Kock Wiil were involved in the six field studies. We are indebted to the workers and managers at the six companies for having given the project their support, their interest, and their time. Thanks to the anonymous reviewers for very relevant comments and suggestions.

\section{REFERENCES}

Blauner, R.: Alienation and Freedom: The Factory Worker and His Industry, University of Chicago Press, Chicago, 1964.

Braverman, Harry: Labor and Monopoly Capital. The Degradation of Work in the Twentieth Century, Monthly Review Press, New York and London, 1974.

Carstensen, Peter H., Schmidt, K., and Wiil, U. K.: "Supporting shop floor intelligence: A CSCW approach to production planning and control in flexible manufacturing," in S. C. Hayne (ed.): GROUP'99 - International ACM SIGGROUP Conference on Supporting Group Work, Phoenix, Arizona, ACM, 1999, pp. 111-120.

Carstensen, Peter H., and Sørensen, C.: "From the social to the systematic. Mechanisms supporting coordination in design," Computer Supported Cooperative Work. The Journal of Collaborative Computing, vol. 5, no. 4, 1996, pp. 387-413.

Durand, J.-P., Stewart, P., and Castillo, J. J. (eds.): Teamwork in the Automobile Industry: Radical Change or Passing Fashion?, Macmillan etc., 1999.

Grinter, Rebecca E.: "Doing software development: Occasions for automation and formalisation," in J. A. Hughes at al. (eds.): ECSCW '97. Proceedings of the Fifth European Conference on ComputerSupported Cooperative Work, 7-11 September 1997, Lancaster, U.K., Kluwer Academic Publishers, Dordrecht, 1997, pp. 173-188.

Gunn, Thomas G.: Computer Applications in Manufacturing, Industrial Press, New York, 1981.

Gunn, Thomas G.: Manufacturing for Competitive Advantage. Becoming a World Class Manufacturer, Ballinger, Cambridge, Mass., 1987.

Harrington, Joseph: Computer Integrated Manufacturing, Krieger, Malabar, Florida, 1979.

Harrington, Joseph: Understanding the Manufacturing Process. Key to Successful CAD/CAM Implementation, Marcel Dekker, New York, 1984.

Hirschhorn, Larry: Beyond Mechanization: Work and Technology in a Postindustrial Age, The MIT Press, Cambridge, Mass. - London, 1984.

Odgaard, Irene: In practise it was worse than expected. Production groups at Aalestrup, Grundfos, Denmark. A case study on new forms of work organization. [in Danish], General Workers' Union in Denmark, 1994.

Orlikowski, Wanda J.: "CASE Tools as Organizational Change: Investigating Incremental and Radical Changes in Systems Development," MIS Quaterly, no. September 1993, 1993, pp. 309-340.

Patton, M. Q.: Qualitative Evaluation Methods, Sage Publications, Beverly Hills, CA, 1980.

Schmidt, Kjeld: "Riding a Tiger, or Computer Supported Cooperative Work," in L. Bannon, M. Robinson, and K. Schmidt (eds.): ECSCW '91. Proceedings of the Second European Conference on Computer-Supported Cooperative Work, Kluwer Academic Publishers, Amsterdam, 1991, pp. $1-16$.

Schmidt, Kjeld: "Of maps and scripts: The status of formal constructs in cooperative work," Information and Software Technology, vol. 41, 1999, pp. 319-329.

Suchman, Lucy A.: Plans and situated actions. The problem of human-machine communication, Cambridge University Press, Cambridge, 1987.

Todd, Robert H., Dell K. Allen, and Leo Alting: Fundamental Principles of Manufacturing Processes, Industrial Press, New York, 1994a.

Todd, Robert H., Dell K. Allen, and Leo Alting: Manufacturing Processes Reference Guide, Industrial Press, New York, 1994b.

Womack, James P., Daniel T. Jones, and Daniel Roos: The Machine that Changed the World: The Story of Lean Production, Rawson Associates, New York, 1990.

Yin, Robert K.: Case Study Research: Design and Methods, Sage Publications, Beverly Hills, 1989. 